\title{
Effect of length and insertion angle on stability of miniscrews used for retraction of anterior teeth-an in vitro study
}

\author{
Deepak Paul $^{1 *}$, Snehlata Verma², Rohit Khanna ${ }^{3}$, Tripti Tikku ${ }^{4}$, R P Maurya ${ }^{5}$, Kamna Srivastava ${ }^{6}$, Anshul \\ Srivastava $^{7}$
}

${ }^{1}$ Junior Resident, ${ }^{\mathbf{2 , 5}, 6}$ Reader, ${ }^{3}$ Professor, ${ }^{4}$ Professor and Head, ${ }^{7}$ Lecturer, Dept. of Orthodontics and Dentofacial Orthopedics, Babu Banarasi Das College of Dental Sciences, Lucknow, Uttar Pradesh, India

*Corresponding Author: Deepak Paul

Email: drdeepakpaul@gmail.com

\begin{abstract}
Aim: To assess the effect of length and insertion angle on stability of mini screw in synthetic bone replica used for retraction of anterior teeth.

Materials and Methods: A total of 120 titanium miniscrews (SK Surgicals) were equally divided into two groups based on their insertion in synthetic replica of bone (ORTHOBONES, 3B scientific, Germany) i.e. maxillary (Group I) or mandibular (Group II) bone. Both the groups were further divided into 8 subgroups based on length and angulation i.e. Ia60 $\left(8 \mathrm{~mm}, 60^{\circ}\right)$, Ia90 $\left(8 \mathrm{~mm}, 90^{\circ}\right)$, Ib60 $\left(11 \mathrm{~mm}, 60^{\circ}\right)$,

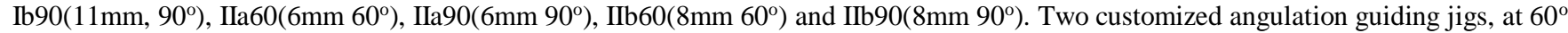
and $90^{\circ}$ angle were fabricated. Miniscrew was driven into the bone using the screwdriver. A Universal testing machine was used to conduct Shear Compressive Strength test on all the Miniscrews. Data was collected and ANOVA and Post Hoc Test were applied to get the results.

Result: For maxillary bone analogue (Group I), $11 \mathrm{~mm}$ miniscrew inserted at $90^{\circ}$ angulation had maximum values and $8 \mathrm{~mm}$ screws at $60^{\circ}$ had minimum values of SCS. The trend for SCS of miniscrews in Group I was Ib90>Ib60>Ia90>Ia60. In mandibular bone analogue, 8 $\mathrm{mm}$ miniscrews inserted at $90^{\circ}$ angulation showed maximum stability and $6 \mathrm{~mm}$ at $60^{\circ}$ showed minimum SCS. The trend for SCS in Group II was IIb90>IIa90>IIb60>IIa60. Intergroup comparison revealed that statistical difference for IIb60 $>\mathrm{Ia60}$, Ilb90>Ia90, IIb90>Ia60 and IIb60>Ia90 which suggest that MS inserted in mandibular analogue had better SCS than in maxilla irrespective of angulation.

Conclusion: Longer miniscrews inserted perpendicular to the bone gives maximum stability. It is also found that stability increases with increase in cortical bone thickness.
\end{abstract}

Keywords: Miniscrews, Bone, Shear compressive strength, Primary stability, TAD, Bone analogue.

\section{Introduction}

Anchorage control is an important factor in the successful outcome of any Orthodontic treatment. Teeth as an anchorage unit provide simple or stationary anchorage by taxing larger posterior teeth against relatively smaller anterior teeth or including second molars in the anchorage unit so as to avoid undesired tooth movement.

Toward the end of the 1980s, a number of clinicians focused on the use of standard dental implants not only as permanent abutments ${ }^{8-12}$ for tooth replacement but also skeletal anchorage for orthodontic tooth movement. The disadvantages of dental implants are the need for an invasive surgical procedure, the time required for Osseo integration prior to force application, and cost. ${ }^{8}$ To obviate these limitations, implants were specifically designed for use in orthodontics and were termed as TAD (Temporary Anchorage Device).

To the best of our knowledge, none of the studies used synthetic bone analogue mimicking the characteristic thickness of cortical and cancellous bone of the mandible and maxilla separately to check the primary bone stability of miniscrews. Hence it is decided to assess the two most important mechanical factors i.e. optimal length and angle of insertion for the stability of mini screw as Temporary anchorage device in orthodontics.

Considering this, the aim of the present in vitro study will be to assess the effect of length and insertion angle on the stability of mini screws in synthetic bone replica used for retraction of anterior teeth using shearing compressive force.

\section{Materials and Methods}

A total of 120 titanium miniscrews (MS) of different lengths were equally divided into two groups based on their insertion in synthetic replica of boneie maxillary or mandibular bone. Both the groups were further divided into 2 subgroups according to the length of miniscrews inserted in maxilla and mandible.

Group IA: Miniscrews (MS) of $8 \mathrm{~mm}$ length inserted in maxillary synthetic bone.

Group IB: Miniscrews (MS) of $11 \mathrm{~mm}$ length inserted in maxillary synthetic bone.

Group IIA: Miniscrews (MS) of $6 \mathrm{~mm}$ length inserted in mandibular synthetic bone.

Group II B: Miniscrews (MS) of $8 \mathrm{~mm}$ length inserted in mandibular synthetic bone.

For each subgroup, miniscrews were inserted at two different angulations i.e. $\left(60^{\circ}\right.$ and $\left.90^{\circ}\right)$ thereby further subdividing subgroups as Ia60, Ia90, Ib60, Ib90, IIa60, IIa90, IIb60 and IIb90.

The methodology used in the study is described under following headings.

\section{Fabrication of guiding jig}

i. Two customized angulation guiding jigs one at $60^{\circ}$ and other at $90^{\circ}$ angle were fabricated to establish the 
correct angulation while inserting the miniscrews in synthetic bone replica.

ii. Two 19 guage wires are soldered at 60 and 90 degrees and polished to make the framework. A transparent body of refill pen was used as hard plastic tube to direct the ratchet at desired angulation while inserting the miniscrew in synthetic bone analogue. The diameter of the tube should be such that the anterior portion of the ratchet snuggly fits into it and allows for free movement of ratchet. To stabilize the base wire of jig, acrylic blocks were made on each side using wax framework. Then the wax was removed and acrylic was polished as shown in Fig. 1 such that the customized jig was ready to use.

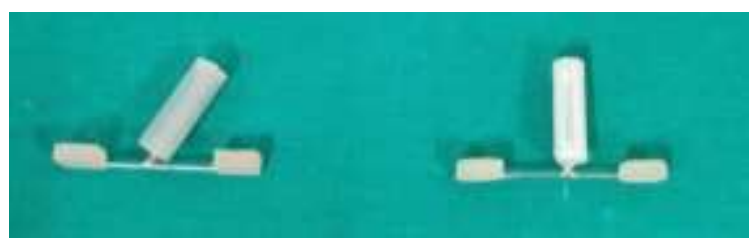

Fig. 1: Customized guiding jig

\section{Placement of miniscrews}

For placement of miniscrew, it was loaded in the miniscrew driver. Then head of the screwdriver is passed throught the plastic tubing of the guiding jig and the tip of miniscrew is placed at the desired point on the bone analogue. To prevent movement of jig at this point in desired angulation, acrylic blocks attached to base of jig was stabilized by figure pressure. After stabilization and location of jig at desired point, Miniscrew was driven in the bone by turning screwdriver in clockwise direction till the head portion of miniscrew approximated the surface of bone. Similar procedure was repeated for all the screws at desired angulation using the guiding jig as shown in Fig. 2.

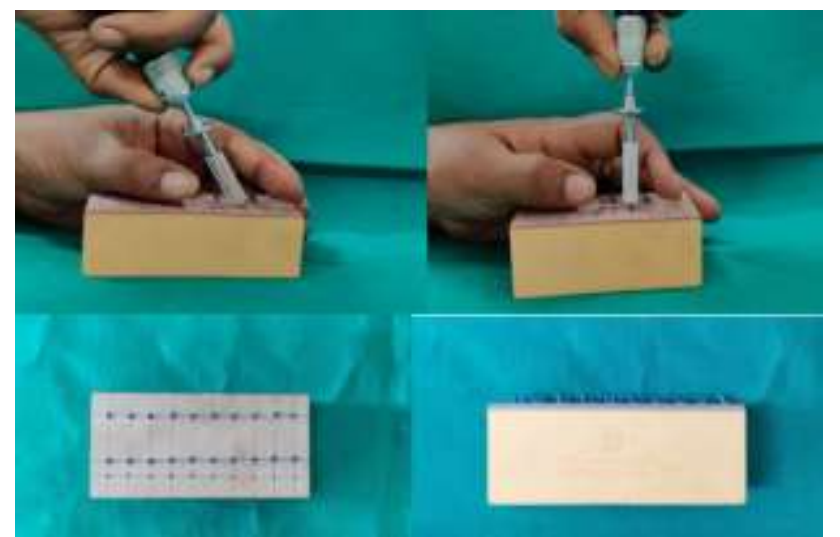

Fig. 2: Placement of miniscrews in synthetic bone analogue at $60^{\circ}(\mathrm{A})$ and $90^{\circ}(\mathrm{B})$ with the help of customized guiding jig

\section{Shear compressive strength test and statistical analysis}

A small-scale loading machine, Universal testing machine (Central Institute of Plastics Engineering and Technology, Lucknow) was used to apply force to the miniscrews. Bone blocks were placed in the machine with the miniscrews oriented tangent to the load cell secured with bench vise grips and a backing plate to counteract block rotation. Force was applied to the implants at a rate of $2 \mathrm{~mm} / \mathrm{sec}$ until failure of retention occurred (Fig. 3). Peak load force to failure was obtained and the data was recorded.

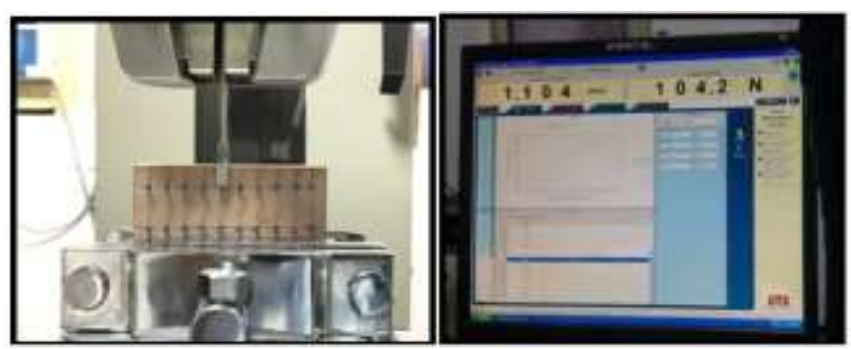

Fig. 3: Placement of block in Instron machine for assessment of shear compressive strength.

Data was collected and suitable statistical tools were applied to get the results.

\section{Results}

The results of this study showed that, in maxillary bone analogue (Group I), $8 \mathrm{~mm}$ screw inserted at 90 degrees angulation showed a mean value of shear compressive strength (SCS) as 82.60 $\pm 12.040 \mathrm{~N}$, whereas $8 \mathrm{~mm}$ screw inserted at 60 degree angulation showed a value of $74.07 \pm 9.714 \mathrm{~N}$. For $11 \mathrm{~mm}$ screw, SCS at 90 degree angulation showed a value of $105.87 \pm 19.453$, whereas at 60 degree angulation it showed a value of $91.53 \pm 13.569 \mathrm{~N}$. The trend seen for Group I was Ib90>Ib60>Ia90>Ia60.

In mandibular bone analogue (Group II), $6 \mathrm{~mm}$ screw at 90 degrees showed a mean value of SCS as 103.53 $14.788 \mathrm{~N}$, whereas $6 \mathrm{~mm}$ screw at 60 degree angulation showed a mean value of SCS as $84.00 \pm-16.423 \mathrm{~N} .8 \mathrm{~mm}$ screw at 90 degrees showed a value of $109.27 \pm 10.437 \mathrm{~N}$, whereas $8 \mathrm{~mm}$ screw at 60 degree angulation showed a value of $101.40 \pm-13.146 \mathrm{~N}$. The trend seen for Group II was IIb90 $>$ IIb60 $>$ IIa90 $>$ IIa60.

Though, on comparing MS of $8 \mathrm{~mm}$ length placed at $60^{\circ}(\mathrm{Ia} 60)$ and $90^{\circ}(\mathrm{Ia} 90)$ degree angulation in maxillary bone analogue, mean SCS was found to be more at $90^{\circ}$ angulation than $60^{\circ}$ with a mean difference of 8.533 but the difference was statistically non-significant. $(\mathrm{p}=0.708)$

Similarly on comparing MS of $11 \mathrm{~mm}$ length at 60(Ib60) and 90(Ib90) degree angulation, mean SCS was found to be more at $90^{\circ}$ angulation with a mean difference of 4.4 , but the difference was again statistically nonsignificant. $(\mathrm{p}=0.988)$

On comparing $8 \mathrm{~mm}$ screws at 60 degree angulation (Ia60) and $11 \mathrm{~mm}$ at 90 degree angulation (Ib90), mean SCS was found to be more in MS of $11 \mathrm{~mm}$ length at $90^{\circ}$ with a mean difference of 31.8 which was statistically significant. $(\mathrm{p}=0.000)$

Though, on comparing MS of $6 \mathrm{~mm}$ length placed at $60^{\circ}$ (IIa60)and $90^{\circ}$ degree angulation(IIa90) in mandibular bone analogue, mean SCS was found to be more at $90^{\circ}$ 
angulation than $60^{\circ}$ a mean difference of 12.000 but the difference was statistically non-significant. $(\mathrm{p}=0.279)$

Though, on comparing MS of length $6 \mathrm{~mm}$ inserted at 90 degree angulation (IIa90) and MS of length $8 \mathrm{~mm}$ inserted at 60 degree angulation (IIb60), mean SCS was found to be more in MS of length $8 \mathrm{~mm}$ inserted at $60^{\circ}$ than MS of length $6 \mathrm{~mm}$ inserted at $90^{\circ}$ with a mean difference of 9.867 but the difference was statistically nonsignificant. $(\mathrm{p}=0.535)$

On comparison of Group I and Group II for MS of length $8 \mathrm{~mm}$ inserted at $60^{\circ}$ angulation(Ia60 and IIb60), mean SCS was found to be more in Group II that Group I with a mean difference of $27.333 \mathrm{~N}$ which was statistically significant. $(\mathrm{p}=0.000)$

On comparison of Group I and Group II for MS of length $8 \mathrm{~mm}$ inserted at $90^{\circ}$ angulation (Ia90 and IIb90), mean SCS was found to be more in Group II that Group I with a mean difference of $26.667 \mathrm{~N}$ which was statistically significant. $(\mathrm{p}=0.000)$

On comparing MS of length $8 \mathrm{~mm}$ inserted at $60^{\circ}$ angulation for Group I (Ia60) and at $90^{\circ}$ angulation for group II(IIb90), mean SCS was found more in MS of $8 \mathrm{~mm}$ length inserted at $90^{\circ}$ angulation in mandible with a mean difference of 35.200 which was statistically significant. $(\mathrm{p}=0.000)$

On comparing MS of length $8 \mathrm{~mm}$ inserted at $90^{\circ}$ angulation for Group I (Ia90) and at $60^{\circ}$ angulation for group II(IIb60), mean SCS was found more in MS of $8 \mathrm{~mm}$ length inserted at $60^{\circ}$ angulation in mandible with a mean difference of 18.800 which was statistically significant. $(\mathrm{p}=0.009)$

\section{Discussion}

The success of any miniscrew depends on its primary retention and subsequent stability of miniscrew over a period when orthodontic mechanics continue.

Many suggestions have been given in literature for increasing the stability of miniscrews like use of conical shaped screws, ${ }^{13}$ using screws with wide diameter ${ }^{14}$ and increased length, ${ }^{13,15-18}$ achieving partial osseointegration, ${ }^{19}$ inserting at 60-70 degree angulation, ${ }^{20,21}$ applying 5-10 $\mathrm{Ncm}$ insertion torque, ${ }^{21}$ placing in high density bone ${ }^{14,15}$ etc. However evidence based studies are lacking to support the same.

To simulate clinical condition, synthetic bone analogues had been used in previous studies for insertion of miniscrews. Clinically the type of bone differs in maxilla and mandible. Misch in 1988 classified bone as $D_{1} D_{2} D_{3}$ and $\mathrm{D}_{4}$ depending on the difference in bone densities as seen on a CBCT. Anterior mandible $\left(\mathrm{D}_{1}\right)$ has a mean density of $970 \mathrm{HU}>$ Posterior mandible $\left(\mathrm{D}_{2}\right) 669.6 \mathrm{HU}>$ anterior maxilla $666.1\left(\mathrm{D}_{3}\right)>$ Posterior maxilla $\left(\mathrm{D}_{4}\right) 417.3 \mathrm{HU} .^{22}$

Posterior maxilla and mandible are common sites where MS are inserted for maximum anchorage during anterior teeth retraction. Since posterior mandible has more density compared to posterior maxilla, two bone analogues mimicking maxilla and mandible were used in the present study. Katranji et $\mathrm{al}^{23}$ found cortical bone thickness ranges from 1.6-2.2 $\mathrm{mm}$ in dentate maxilla and mandible of cadavers. Moteyoshi et $\mathrm{al}^{24}$ found that cortical bone thickness ranges from $1.09-2.12 \mathrm{~mm}$ in maxilla and 1.54 $3.03 \mathrm{~mm}$ in mandible.

Considering these values of cortical bone thickness seen clinically, two bone analogues of variable cortical bone thickness were taken. Bone analogues had a density of 0.70 $0.75 \mathrm{~g} / \mathrm{cm}$ for cortical bone. Thus bone analogue of $2 \mathrm{~mm}$ thickness of cortical bone will have more density than that of bone analogue of $1 \mathrm{~mm}$ cortical bone thickness. The bone analogue of $2 \mathrm{~mm}$ cortical bone thickness will mimic mandible and bone analogue of $1 \mathrm{~mm}$ thickness will mimic maxilla. ${ }^{15}$

To have uniformity in comparison, all the miniscrews were of same diameter i.e $1.5 \mathrm{~mm}$, which is most commonly used in orthodontics. Miyawaki et $\mathrm{al}^{25}$ found that the diameter of screws was significantly affecting primary stability of the MS. The one year success rate of $1 \mathrm{~mm}$ diameter screws was less than 1.5 and $2.3 \mathrm{~mm}$ screws. The latter two sizes did not differ.

Ashith MV et $\mathrm{al}^{26}$ stated that on comparison of SS and titanium, stainless-steel mini implants had a higher failure rate $(50 \%)$ when compared to titanium mini-implants $(10 \%)$. This is the reason why titanium miniscrews were used in the present study.

On comparison between the different angulations $\left(60^{\circ}\right.$ and $90^{\circ}$ ) and keeping the other variables (length and cortical bone thickness) constant, the present study showed that mini screws at $90^{\circ}$ angulation is more stable than its $60^{\circ}$ counterpart in their respective bone analogue. Park et $\mathrm{al}^{27}$ introduced oblique angle of insertion instead of perpendicular angulaion to avoid root damage as more space was available in the apical region.

The results of this study were consistent with the works done by Petrey JS et al, ${ }^{15}$ Omar A ${ }^{28}$ Lee Jet al. ${ }^{29}$ Petrey et $\mathrm{al}^{15}$ evaluated stability of miniscrews of 3 different companies by pull out test. MS inserted at 2 different angulations, $45^{\circ}$ and $90^{\circ}$. MS at $90^{\circ}$ angulation had values ranging from $7.856 \pm 0.97 \mathrm{~N}$ to $8.805 \pm 0.278 \mathrm{~N}$ in different systems and those inserted at $45^{\circ}$ angulation had values ranging from $4.47+0.15 \mathrm{~N}$ to $5.503+0.44 \mathrm{~N}$. They stated that $90^{\circ}$ placement of miniscrews in cortical bone produced more resistance and more stability. Omar et $\mathrm{al}^{28}$ inserted implant between second premolar and first molars at different angulations $(30,45,50,60,70,80,90)$ and measured von meiss stress (EQV) using FEM. The max EQV observed from 30-90 degrees were $96.93 \mathrm{mPa}, 78.16$ $\mathrm{mPa} \quad 80.72 \mathrm{mPa} \quad 69.05 \mathrm{mPa} \quad 55.35 \mathrm{mPa} \quad 46.54 \mathrm{mPa}$ respectively. It was found that at $90^{\circ}$ angulation, von meiss stresses were minimal. Hence increased primary stability will be expected.

According to these studies, with an oblique insertion angle, contact of screw to cortical bone increases which might favour the stability but cantilever load arm concomitantly lengthens which adversely affects miniscrew stability even at orthodontic force levels. Omar A et $\mathrm{al}^{28}$ and Lee $\mathrm{J}^{29}$ attributed the stability of $90^{\circ}$ angulation to the stress distribution in the cortical bone. They stated that when the 
mini-implant is placed at angle of $90^{\circ}$ to the cortical bone, the von Meiss stresses and displacement of the mini-implant were the least.

Piackard et $\mathrm{al}^{23}$ found mean SCS of $123.8 \pm 26.5 \mathrm{~N}$ at $90^{\circ}$ which is having a better stability than SCS of $102.3 \pm$ $25.4 \mathrm{~N}$ at $45^{\circ}$.

Contrary to this study were the results of the study done by Wilmes $\mathrm{B}$ et $\mathrm{al}^{20}$ and Maya RR et al. ${ }^{21}$ Wilmes et $\mathrm{al}^{20}$ stated that when mini-implants inserted at an angle of $60^{\circ}$ $70^{\circ}$ had maximum insertion torque in comparison to $30^{\circ}$, $40^{\circ}, 50^{\circ}$ and $90^{\circ}$. The parameters evaluated was different. High insertion torque contribute to more failure as often seen in mandible. Maya $\mathrm{RR}$ et $\mathrm{al}^{21}$ found that implants paced at $90^{\circ}$ angulation had greater insertion torque than those inserted at $60^{\circ}$ angulation in maxilla of human cadavers. Minimum amount of insertion torque, ranging between $7-10 \mathrm{NCm}$ is necessary for primary stability. If value are higher than this, it can lead to fracture of cortical bone or screw itself. Maya et $\mathrm{al}^{21}$ found insertion torque values ranging from 11-17 $\mathrm{NCm}$, which is higher than minimum required values. According to the author, MS inserted at $60^{\circ}$ angulation will have less tendency to fracture than those inserted at $90^{\circ}$ angulation

Keeping the other variables (material and angulation) constant, when the effect of length of mini-implants on its primary stability was compared, the results showed that on increasing the length of mini-implants, the stability of miniimplants increased

Congruent with this study was the work done by Kim YK et al, ${ }^{13}$ Kuroda et al ${ }^{16}$ Mohammed HI and Sheakli HA, ${ }^{17}$ Lin et $a{ }^{18}{ }^{18}$ Petrey JS et $\mathrm{al}^{15}$ and Antonzewska ${ }^{14}$ et al. Different authors have postulated different reasons for increasing stability on increasing the length of mini-implant. Kim YK et al ${ }^{13}$ stated that long mini-implant provide higher stability with higher torque during removal. However, the long mini-implant can fracture during insertion because it needed a higher insertion torque. Karoda et $\mathrm{al}^{16}$ found high success rate with longer implants i.e $12 \mathrm{~mm}>10 \mathrm{~mm}>8 \mathrm{~mm}$. Mohammed HI and Sheakli $\mathrm{HA}^{17}$ postulated that the longer anchor length exerted a greater pull out strength and higher primary stability. They attributed it to greater compression of bone on increasing the length and diameter and greater BIC (Bone to implant contact). Lin et $\mathrm{al}^{18}$ found high success rate in $\mathrm{mS}$ of $10-12 \mathrm{~mm}$ length (98\%) in comparison to MS of length 6-7 mm length (82\%) and $8 \mathrm{~mm} \mathrm{(97 \% ).}$ Petrey JS et $\mathrm{al}^{15}$ stated that an increase in length of miniimplant increased the primary stability of the mini-implants. However, they stated that a $6 \mathrm{~mm}$ miniimplants appeared to be sufficient because shorter implants run less risk of damaging roots and their supporting tissues. Antonzewska ${ }^{14}$ in 2009 evaluated success rate of two type of MS system of 2 different length i.e 6 and $8 \mathrm{~mm}$ inserted in maxilla and mandible. The result for implant length showed success rate of $94.79 \%$ with longer MS and $92.65 \%$ with respect to shorter MS. Sarul et al ${ }^{31}$ concluded that MS of $8 \mathrm{~mm}$ length were clinically more stable than $6 \mathrm{~mm}$ length miniscrews in mandible.
Contrary to the present study were the results of works done by Singh AK et $\mathrm{al}^{19}$ and Ohali HA, ${ }^{32}$ Miyawaki et al, ${ }^{25}$ and Wilmes et al. ${ }^{21}$ They stated that increase in length did not affect the stability of mini-implant.

Intergroup comparison revealed increased cortical bone thickness of bone analogue mimicking mandible had better shear compressive strength.

Motoyoshi et $\mathrm{al}^{24}$ suggest a minimum cortical bone thickness of $1 \mathrm{~mm}$ to ensure miniscrew stability. In contrary to our study, Duaibis ${ }^{33}$ in his FEM study did not found significant effect of cortical bone thickness on stresses within the periimplant cortical layer.

Piackard et $\mathrm{al}^{30}$ stated that primary stability is by the buccal cortex. According to them, MS acts as class II lever arm where load is between fulcrum point and the applied load (i.e. apex of MS, as it wedges into lingual cortex acts as fulcrum point). Buccal cortex acts as resisting load and applied load is shear force applied at the head of MS. Hence bone analogue with increased cortical thickness will provide better primary stability as seen in our intergroup comparison. Lin et $\mathrm{al}^{18}$ found better success rate in mandible (98\%) than in maxilla (94.1\%), attributing it to greater cortical bone thickness in mandible than maxilla.

Within the limitation of the present study, it can be suggested that longer miniscrews at $90^{\circ}$ angulation will have better stability in their respective bone blocks. However selection of implant angulation is based on its anatomic location. The MS placed in retromolar and distobuccal bone of mandible and maxilla can be placed at $90^{\circ}$ to bone for increased stability. The reason for this was to reduce root contact by screw implant without reducing the length of screw. However it is not always possible to insert MS at $90^{\circ}$ and angulation approach is recommended. If Buccal alveolar bone volume is adequate relative to the long axis of teeth, MS can be placed at an angle to minimize root contact as more space is there and surface area of cortical bone to MS is increased allowing placement of longer MS for increased primary stability. ${ }^{9}$

Future scope of the study will include validating the results of the study by determining long-term success or failure of MS of variable length, diameter and angulation inserted in patients for different orthodontic mechanisms. Also primary stability of other commercially used MS of different companies of variable length and diameter inserted at variable angulations can be evaluated.

\section{Conclusion}

The clinical application of this study suggests that placement of longer miniscrews at $90^{\circ}$ angulation increase the success rate of the miniscrews by giving a better primary stability. Also it is noted that placement of miniscrews at areas of increased cortical bone thickness increases stability of miniscrews.

\section{Source of Funding}

None. 


\section{Conflict of Interest}

None.

\section{References}

1. Carano A, Velo S, Incorvati C, Poggio P. Clinical applications of the mini-screw-anchorage system (M.A.S.) in the maxillary alveolar bone. Prog Orthod. 2004;5:212-35.

2. Roberts WE, Marshall JK, and Mozsary PG. Rigid endosseous implant utilized as anchorage to protract molars and close an atrophic extraction site. Angle Orthod. 1990;60:135-52.

3. Celenza F. and Hochman MN: Absolute anchorage in Orthodontics: Direct and indirect implant-assisted modalities. $J$ Clin Orthod. 2000;34:397-402.

4. Gray JB, Smith R. Transitional implants for Orthodontic anchorage. J Clin Orthod. 2000;34:659-66.

5. Wehrbein H, Merz BR. Aspects of the use of endosseous palatal implants in Orthodontic therapy. J Esth Dent. 1998;10:315-24.

6. Kim YK, Kim YJ, Yun PY, Kim JW. The effects of the taper shape, dual-thread and length on the mechanical properties of mini-implant. Angle Orthod. 2009;79:908-14.

7. Antoszewska J, Papadopoulos MA, Park HS, Ludwig B. Fiveyear experience with orthodontic miniscrew implants: a retrospective investigation of factors influencing success rates. Am J Orthod Dentofacial Orthop. 2009;136:158.e1-10.

8. Petrey JS, Saunders MM, Kluemper GT, Cunningham LL, Beeman CS. Temporary anchorage device insertion variables: effects on retention. Angle Orthod. 2010;80:446-53.

9. Kuroda S, Sugawara Y, Deguchi T, Kyung HM, Yamamoto TT. Clinical use of miniscrew implants as orthodontic anchorage: Success rates and postoperative discomfort. Am J Orthod Dentofacial Orthop. 2007;131:9-15.

10. Al Sheakli, Iman I, Mohammed, Haneen I. Comparing the Primary Stability of Three Different Orthodontic MiniImplants with Various Dimensions on Artificial Bone. Int J Med Res. 2018;7(1):128-34.

11. Song YL, Mimi Y, Chew MT, Foong KWC, Wong HC. A study of success rate of miniscrew implants as temporary anchorage devices in Singapore. Int J Dent. 2015;29:46-70.

12. Singh AK, Kannan S, Arora N, Bajaj Y, Revankar AV. Measurement of primary stability of mini implants using resonance frequency analysis. APOS Trends Orthod 2018;8:139-45.

13. Wilmes B, Rademacher C, Olthoff G, Drescher D. Parameters affecting primary stability of orthodontic mini-implants. $J$ Orofac Orthop. 2006;67:162-74.

14. Maya RR, Pinzan-Vercelino CR, Gurgel JA. Effect of vertical placement angle on the insertion torque of mini-implants in human alveolar bone. Dent Press J Orthod 2017;21:47-52.

15. Deguchi T, Nasu M, Murakami K, Yabuuchi T, Kamioka H, Takano-Yamamoto T. Quantitative evaluation of cortical bone thickness with computed tomographic scanning for Orthodontic implants. Am J Orthod Dentofacial Orthop. 2006;129(6):721.e7-e12

16. Katranji A, Misch K, Wang HL. Cortical Bone Thickness in Dentate and Edentulous Human Cadavers. J Periodontol. 2007;78:874-8.

17. Motoyoshi M, Hirabayashi M, Uemura, M, Shimizu N. Recommended placement torque when tightening an Orthodontic mini-implant. Clin Oral Implants Res. 2005; 17:109-14.

18. Miyawaki S, Koyama I, Inoue M, Mishima K, Sugahara T, Takano-Yamamoto T. Factors associated with the stability of titanium screws placed in the posterior region for orthodontic anchorage. Am J Orthod Dentofacial Orthop. 2003;124:373-8.

19. Ashith MV, Shetty BK, Shekatkar Y, Mangal U, Mithun K. Assessment of Immediate Loading with Mini-Implant
Anchorage in Critical Anchorage cases between stainless steel versus titanium miniscrew implants: A controlled clinical trial. Biomed Pharmacol J. 2018;11(2):36-43.

20. Park HS, Jeong SH, Kwon OW. Factors affecting the clinical success of screw implants used as orthodontic anchorage. Am J Orthod Dentofac Orthop. 2006;130(1):18-25.

21. Omar A, Ishak MI, Harun MN, Sulaiman E, Kasim NHA. Effects of different angulation placement of mini-implant in orthodontic. Angle Orthod. 2012;83:667e73.

22. Lee J, Kim JY, Choi YJ, Kim KH, Chung CJ. Effects of placement angle and direction of orthopedic force application on the stability of Orthodontic miniscrews. Angle Orthod. 2012;83:667e73.

23. Piackard MB, Dechow P Rossouw PE and Buschang PH. Effects of miniscrew orientation on implant stability and resistance to failure. Am J Orthod Dentofacial Orthop. 2010;137:91-9.

24. Sarul M, Minch, Park HS, Antoszewska-Smith J. Effect of the length of Orthodontic mini-screw implants on their long-term stability

25. Al-Ohali H. Factors Effecting Primary Stability of Miniimplants in Vitro. 1st edition, British Columbia, Vancouver 2017:2-18.

26. Duaibis R, Kusnoto B, Natarajan R, Zhao L Evans C. Factors affecting stresses in cortical bone around miniscrew implants: a three-dimensional finite element study. Angle Orthod. 2012;82:875-80.

How to cite: Paul D, Verma S, Khanna R, Tikku T, Maurya RP, Srivastava K, Srivastava A. Effect of length and insertion angle on stability of miniscrews used for retraction of anterior teeth-an in vitro study. Indian $J$ Orthod Dentofacial Res. 2020;6(1): 